OPEN ACCESS

Edited by:

Christian Dejaco,

Medical University of Graz, Austria

Reviewed by:

Garifallia Sakellariou,

University of Pavia, Italy

Philipp Sewerin,

Heinrich Heine University of

Düsseldorf, Germany

${ }^{*}$ Correspondence:

Ai Lyn Tan

a.l.tan@/eeds.ac.uk

Specialty section: This article was submitted to

Rheumatology,

a section of the journa

Frontiers in Medicine

Received: 22 May 2020

Accepted: 06 July 2020

Published: 12 August 2020

Citation:

Farrow M, Biglands J, Alfuraih AM, Wakefield RJ and Tan AL (2020) Novel

Muscle Imaging in Inflammatory

Rheumatic Diseases - A Focus on Ultrasound Shear Wave Elastography

and Quantitative MRI

Front. Med. 7:434.

doi: 10.3389/fmed.2020.00434

\section{Novel Muscle Imaging in Inflammatory Rheumatic Diseases-A Focus on Ultrasound Shear Wave Elastography and Quantitative MRI}

\author{
Matthew Farrow ${ }^{1,2,3}$, John Biglands ${ }^{2,4}$, Abdulrahman M. Alfuraih ${ }^{5}$, Richard J. Wakefield ${ }^{1,2}$ \\ and Ai Lyn Tan ${ }^{1,2 *}$ \\ 1 Leeds Institute of Rheumatic and Musculoskeletal Medicine, Chapel Allerton Hospital, University of Leeds, Leeds, \\ United Kingdom, ${ }^{2}$ NIHR Leeds Biomedical Research Centre, Leeds Teaching Hospitals NHS Trust, Leeds, United Kingdom, \\ ${ }^{3}$ School of Pharmacy and Medical Sciences, University of Bradford, Bradford, United Kingdom, ${ }^{4}$ Medical Physics and \\ Engineering, Leeds Teaching Hospitals NHS Trust, Leeds, United Kingdom, ${ }^{5}$ Radiology and Medical Imaging Department, \\ Prince Sattam Bin Abdulaziz University, Al-Kharj, Saudi Arabia
}

In recent years, imaging has played an increasing role in the clinical management of patients with rheumatic diseases with respect to aiding diagnosis, guiding therapy and monitoring disease progression. These roles have been underpinned by research which has enhanced our understanding of disease pathogenesis and pathophysiology of rheumatology conditions, in addition to their key role in outcome measurement in clinical trials. However, compared to joints, imaging research of muscles is less established, despite the fact that muscle symptoms are very common and debilitating in many rheumatic diseases. Recently, it has been shown that even though patients with rheumatoid arthritis may achieve clinical remission, defined by asymptomatic joints, many remain affected by lingering constitutional systemic symptoms like fatigue, tiredness, weakness and myalgia, which may be attributed to changes in the muscles. Recent improvements in imaging technology, coupled with an increasing clinical interest, has started to ignite new interest in the area. This perspective discusses the rationale for using imaging, particularly ultrasound and MRI, for investigating muscle pathology involved in common inflammatory rheumatic diseases. The muscles associated with rheumatic diseases can be affected in many ways, including myositis - an inflammatory muscle condition, and myopathy secondary to medications, such as glucocorticoids. In addition to non-invasive visual assessment of muscles in these conditions, novel imaging techniques like shear wave elastography and quantitative MRI can provide further useful information regarding the physiological and biomechanical status of the muscle.

Keywords: muscle, myositis, myopathy, MRI, ultrasound, shear wave elastography, imaging, rheumatic 


\section{INTRODUCTION}

Advances in diagnostic imaging in rheumatology, particularly in the area of arthritis, have contributed to significant clinical benefits to patients and improved knowledge in disease pathogenesis. Despite the usefulness of ultrasound and magnetic resonance imaging (MRI) in diagnosing arthritis and monitoring disease progression in joints and related joint structures, the role of muscle imaging has conventionally been centered around the diagnosis of inflammatory muscle diseases. However, with an increasing appreciation of the impact and prevalence of muscular symptoms in rheumatic diseases (1), and as a result of technological developments, recent attention has been directed toward the utility of imaging for the assessment of muscle pathology in rheumatic diseases.

The impact of muscle weakness is significant for the health of patients and is associated with disease activity (2). There is an unmet need for further understanding of more generalized muscle pathology observed in rheumatic diseases. This is required to develop effective future strategies to target this under-researched area. In addition to ultrasound and MRI, positron emission tomography combined with computed tomography (PET-CT) is increasingly used in clinical practice to aid the diagnosis of myositis, with the added advantage that this technique can screen for malignancy and evaluate related pulmonary pathologies $(3,4)$. This perspective will discuss recent novel imaging developments in ultrasound and MRI for the assessment of muscles in common inflammatory rheumatic diseases, with a particular focus on research applicability of shear wave elastography and quantitative MRI in improving the knowledge of muscle pathology in rheumatic diseases. The potential application of these novel techniques will be explored in the context of three common inflammatory rheumatology conditions where the muscle is of interest. The first is in myositis, a primary inflammatory condition of the muscle; the second is in glucocorticoid-induced myopathy, where patients with giant cell arteritis and polymyalgia rheumatica are at risk from the complications of prolonged high dose steroid therapy; and the third is rheumatoid arthritis where patients often complain of muscle related symptoms in addition to their joints.

\section{MUSCLE IMAGING TECHNIQUES}

\section{Ultrasound}

Due to recent innovations, ultrasonography has evolved from demonstrating mainly anatomical details to elucidating the physical properties of tissues. Although B-mode ultrasonography has been shown to be reliable in assessing muscle mass and quality (5-7), and muscle fibers during dynamic scanning $(8,9)$, recent interest has been directed to a new type of ultrasound called elastography (10). This technique provides a measure of the stiffness of tissue (11). The first generation machines, developed in the 1990's utilized "strain elastography," where a mechanical ultrasound pulse was generated by repeated probe compressions on the skin by the operator. The returned waves could be used to qualitatively estimate stiffness by comparing the pre- and post-compression tissue deformations. The images were represented as a color map, superimposed on a B-mode image (blue-hard, and red-soft). Shear wave elastography (SWE) has more recently been introduced to offer quantitative measurements by monitoring the velocity of the shear waves generated by strong acoustic pulses. The physics behind shear waves is complex and beyond the scope of this article, but essentially, the velocity of the shear wave increases proportionally with Young's elasticity modulus. SWE is less operator dependent than strain elastography, and offers more objective outcomes. Hence, this perspective will focus on the potential uses of SWE, which has more commonly been established for examining breast, liver, thyroid and prostate tissues (12-14).

In the musculoskeletal setting, SWE has largely been used to study tendinopathies $(15,16)$. More recently however, SWE has been extended to examining muscles, and has been shown to be a reliable tool to measure muscle stiffness (17-19). The technique has been used in the sports and exercise scenarios, to assess muscle injuries and the effect of exercise interventions on muscles $(20,21)$. Clinically, SWE of muscles, such as of the rotator cuff muscles that are commonly susceptible to tears, has been shown to inform appropriate management strategies (22). In the hospital setting, it has shown good reliability for monitoring the muscles of critically ill patients (23). Other clinical uses of SWE are in the assessment of the muscles in neuromuscular conditions including Parkinson's disease, Duchene muscular dystrophy, and in post-stroke spasticity (2426). Insight into the potential of using SWE in assessing muscle elasticity has prompted recommendations into standardizing the technique for optimal data acquisition (27-29). It is known that muscles change with age, which is apparent in the structure and the function of the muscles $(30,31)$. Although some studies using SWE have shown that there is a decline in muscle stiffness with age (32-35), this observation was not corroborated by others (3638). These studies looked at different muscles, which may have influenced the final outcomes, as it has been found that SWE findings may be muscle-dependent (39).

\section{MRI}

MRI offers the ability to examine deeper tissue structures compared to ultrasound. Although MRI can also measure the elasticity of muscles using magnetic resonance elastography (40$44)$, the cost of the technique is more prohibitive when compared to SWE; thus far, the utility of MRI in assessing muscle elasticity is still debatable (45).

Due to its excellent spatial and contrast resolution, MRI can evaluate a wide array of muscle pathologies including muscle injury (46) and soft tissue masses (47). MRI is beginning to have a role in the diagnosis and monitoring of muscle disease and in guiding muscle biopsy $(48,49)$. Whole-body MRI can help identify muscular involvement over large anatomical regions (50, 51). Aside from conventional MRI there is also an important role for quantitative MRI (qMRI) measurements, such as fat fraction, T2 measurement and diffusion tensor imaging (DTI), in muscle imaging. Quantitative MRI can provide information about tissue microstructure that may not be apparent in conventional MRI. It provides objective measurements, as opposed to a qualitative 
A

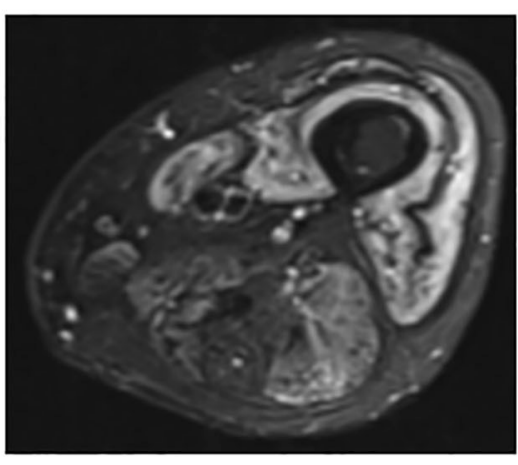

c

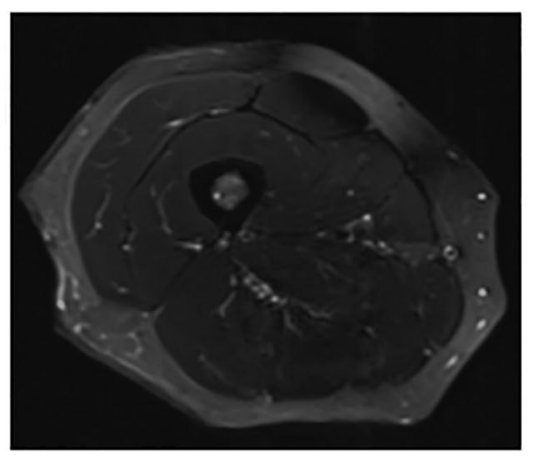

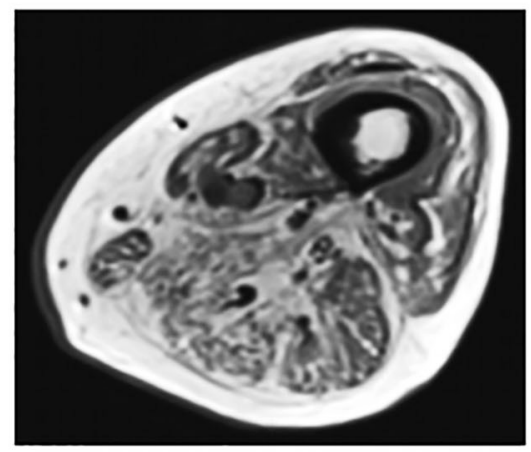

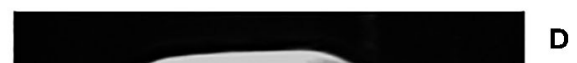

FIGURE 1 | Conventional MRI of the right thigh in (A) T2-STIR and (B) T1-weighted images of a 60-years-old male with active myositis, compared to (C) T2-STIR and (D) T1-weighted images of a 45-years-old healthy female.

assessment and has been shown to be reliable and reproducible in the muscle $(52,53)$.

Fat fraction measurements exploit the differences in the resonant frequencies between the MR signals of fat and water in order to generate a measurement of the proportion of fat in each voxel in the image (54). These measurements provide an objective assessment of fatty infiltration in muscle, which is a common pathology in muscle disease.

Measurements of the T2-relxation time also have applications in the muscle. T2, or the spin-spin relaxation time, is one of the fundamental contrast mechanisms in MRI. By measuring the signal at multiple echo times, measurements of $\mathrm{T} 2$ can be made within the muscle. Raised T2 is often interpreted as increased fluid due to edema or inflammation. However, care must be taken in the interpretation of T2. Fat can also increase T2 values and fat suppression is challenging in T2 measurements $(55,56)$, with some papers arguing that T2 may actually decrease with disease activity (57).

Diffusion MRI is able to measure water diffusion in the muscle. Diffusion measurements in inflamed muscle may be greater due to increased fluid in the extracellular space. Diffusion tensor imaging (DTI) allows the anisotropy of the diffusion to be assessed. As muscle is made up of long fibers, or fibrils, muscle diffusion is highly anisotropic and ordered. As muscle diameters are relatively wide, long diffusion times are necessary if the measurements are to be sensitive to restricted diffusion across the fiber. Fiber disorganization and deterioration through trauma or disease can be detected by DTI measurements, such as fractional anisotropy (FA) (26). However, the interpretation of what a change in diffusion measurement means is difficult. Fiber disorder, fiber density, fiber diameter $(58,59)$ and changes in extracellular water (60) can all affect diffusion parameters. There is on-going research into the use of modeling to analyse DTI acquisitions at multiple diffusion times to separate out different properties of the muscle microstructure from diffusion measurements (61-63).

In the clinical setting, qMRI of various tissues including muscles shows potential as a promising biomarker for assessing and monitoring a range of neuromuscular and musculoskeletal diseases $(57,64-68)$. In general, these patients show higher muscle fat fractions, smaller muscle volume, and increased T2 measures, which also correlate with muscle function (69).

\section{MUSCLE IMAGING IN INFLAMMATORY RHEUMATIC DISEASES}

\section{Myositis}

The idiopathic inflammatory myopathies (IIM) are the commonest inflammatory muscle diseases seen by rheumatologists. They are a heterogeneous group of autoimmune inflammatory muscle conditions comprising mainly of dermatomyositis and polymyositis, which present with muscle weakness, raised muscle enzymes, abnormal electromyography (EMG), abnormal muscle biopsies and myositis-related antibodies (70). 

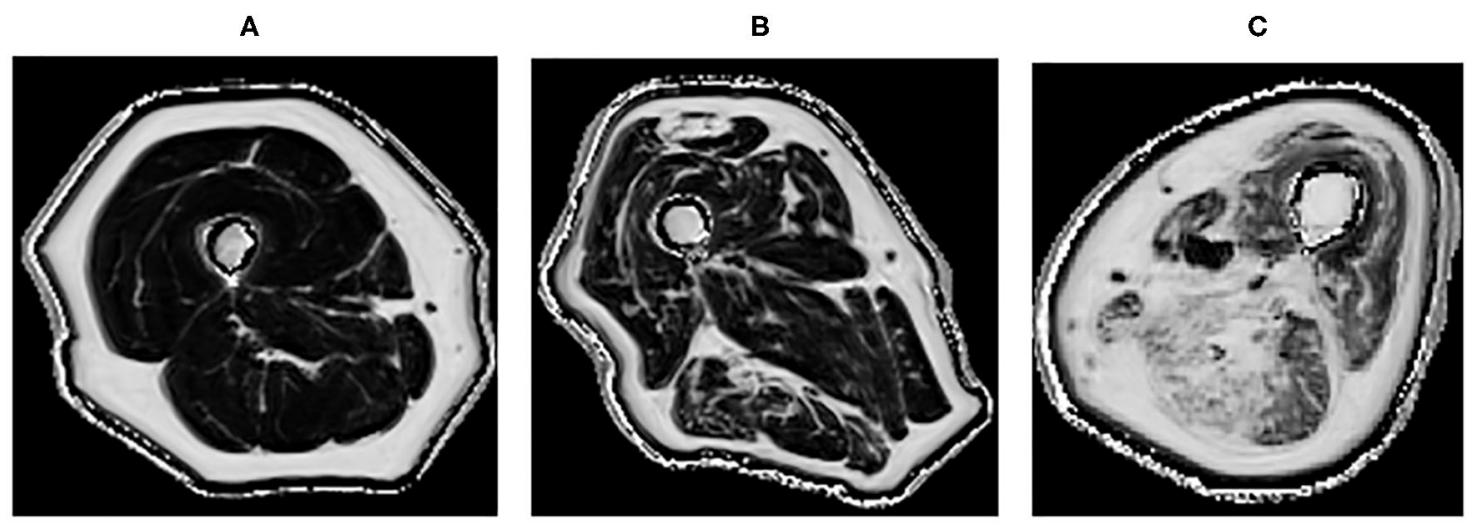

FIGURE 2 | Quantitative MRI fat fraction measurement in the quadriceps and hamstrings, respectively in the thigh in (A) 45-years-old healthy female with a fat fraction of 1.9 and $2.7 \%$, respectively, (B) 83 -years-old healthy male presenting with fatty infiltration associated with healthy aging with a fat fraction of 9.6 and $13.4 \%$, respectively, (C) 60-years-old male with active myositis presenting with fatty infiltration with a fat fraction of 19.6 and $28.5 \%$, respectively.

MRI has become an integral imaging tool in the clinical diagnosis and monitoring of disease activity of myositis due to its ability to non-invasively detect abnormal muscles and identify the most suitable site for muscle biopsies (Figure 1) $(45,71-$ 74). Reassuringly, MRI findings in myositis correlate well with biopsy results (75), and whole body MRI can be more sensitive than muscle enzymes and EMG in diagnosing myositis (76). Nevertheless, the image interpretation can be subjective (77), there is no validated MRI protocol for assessing myositis (45) and MRI findings in isolation may not be specific enough for diagnostic purposes (78).

Quantitative MRI, which allows further characterization of the muscle structure at a microscopic level, can provide a more precise description of muscle pathology $(55,73,79)$. It could potentially be used in longitudinal monitoring of disease (80). It has been demonstrated that $\mathrm{T} 2$ and fat fraction increase in myositis patients (Figure 2), demonstrating that MRI is sensitive enough to quantitatively detect muscle edema (55, 81) and myosteatosis (82). These measures could be used to more accurately guide muscle biopsies. This may be of greater importance in patients with low grade inflammation, where there are subtle muscle changes that might go undetected by conventional MRI. DTI measurements are sensitive to subtle changes in the muscle, and have been used to detect differences in muscle due to diseases including myositis (83). However, muscle DTI is far from standardized. The optimal methods and parameters for performing diffusion in muscle have not been established and larger studies are necessary to establish whether diffusion will be a useful tool for monitoring muscle disease in clinical practice.

One of the drawbacks of MRI as an imaging tool is its cost. Often, this is the deciding factor in choosing ultrasonography over MRI as a more feasible modality in assessing articular joints. But does this cost consideration translate to examining muscles or in patients with myositis? In addition to the more favorable cost compared to MRI, ultrasound also has a greater acceptability by patients. Although there is greater operator dependence for ultrasound, there is the possibility to apply the ultrasound information directly in the clinical setting. There is a suggestion that ultrasound elastography of muscles may be able to aid diagnosis of myositis and its follow-up (84), but the impression is that ultrasound is unlikely to replace MRI in the clinical setting in myositis just yet, because the current evidence is not strong, due to small sample sized studies that results in inconclusive findings (85).

Nevertheless, the current evidence suggests that SWE shows less muscle stiffness in myositis compared to healthy individuals (Figure 3), and can distinguish myositis from normal muscles (86). The loss of muscle stiffness in myositis patients was also observed using magnetic resonance elastography (87). SWE measurements also correlate with muscle strength and MRI grades of edema and atrophy $(86,88)$. All of these findings appear to only manifest when the muscles are under no passive or active loading.

IIM can be a very disabling condition. The potential to use promising non-invasive diagnostic and monitoring tools like qMRI and SWE could facilitate prompt diagnosis and treatment for patients. In the diagnosis of giant cell arteritis (GCA) (89), ultrasound can now reliably replace invasive temporal artery biopsies in GCA diagnosis. Similarly, the continuing development of qMRI and SWE of muscle could 1 day replace muscle biopsy in the diagnosis of IIM.

\section{Steroid Myopathy}

Glucocorticoids are powerful anti-inflammatory agents and have a variety of uses in rheumatology, most commonly as bridging therapy before other longer term treatments are started. Polymyalgia rheumatic (PMR) and the related GCA are two examples where high doses of steroids are prescribed. As a result, many often develop a proximal myopathy, without typical inflammatory laboratory markers, such as muscle enzyme abnormalities or myositis-related antibodies. These patients are often disabled by muscle weakness from the disease process. It would, therefore, be reasonable to hypothesize that, despite 


\section{A}

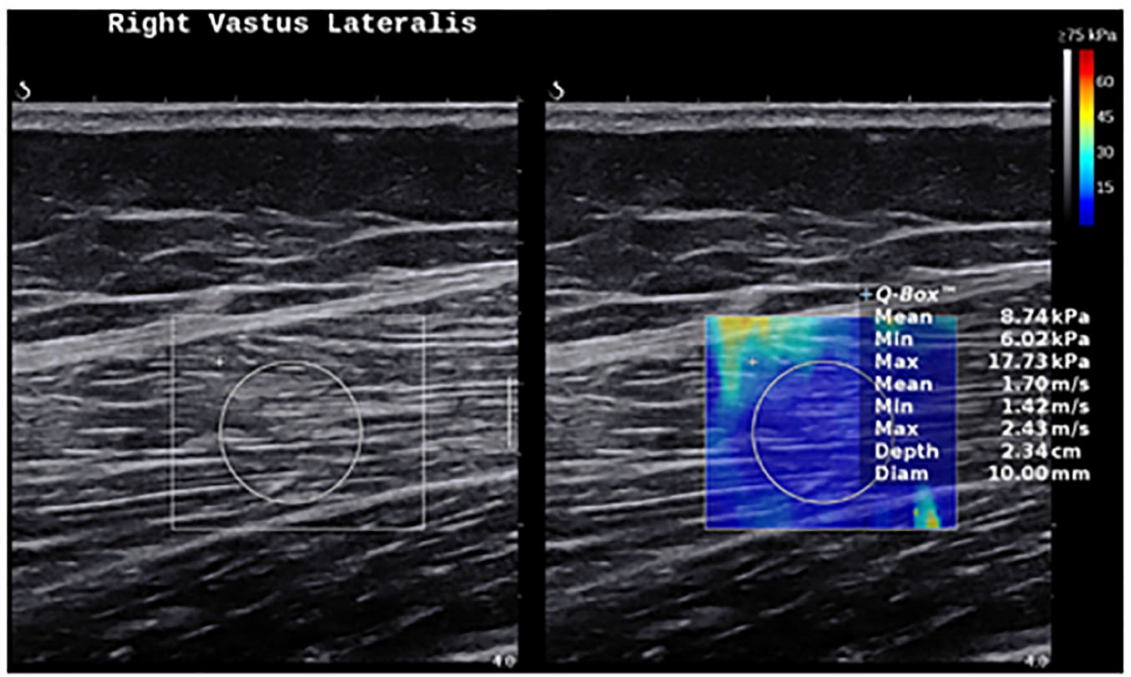

B

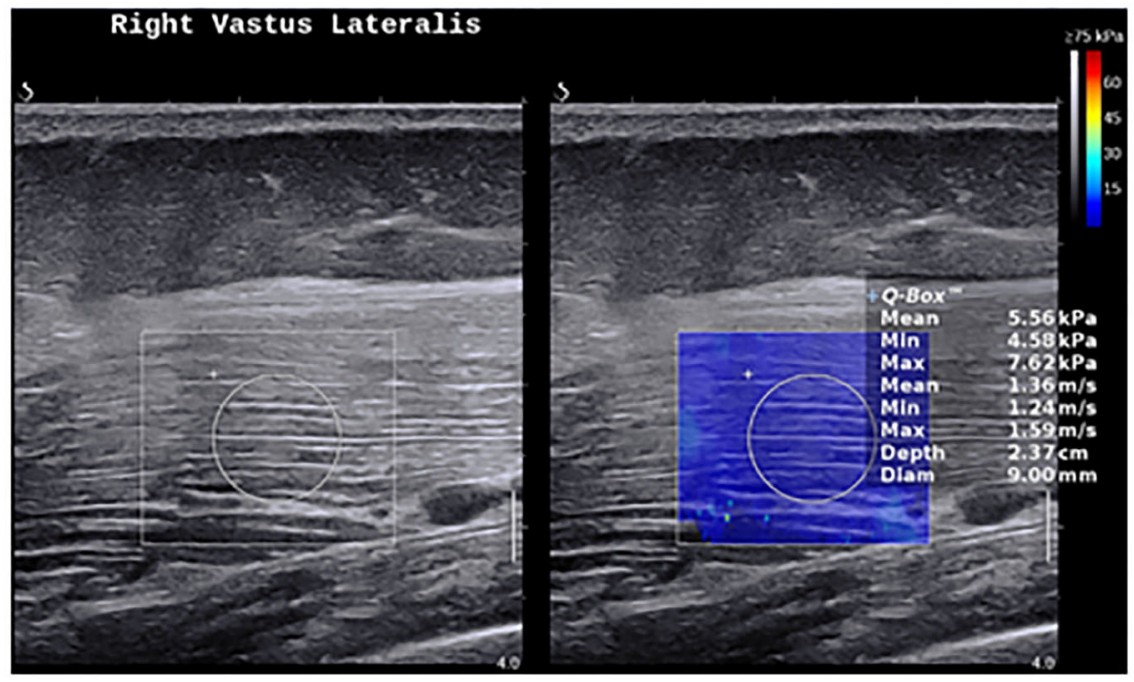

FIGURE 3 | Shear wave elastography in healthy muscles and myositis. (A) Shows a normal muscle stiffness (8.7 kPa) in a 50-year-old healthy female person. (B) Shows a low muscle stiffness $(5.5 \mathrm{kPa})$ in a 49 -year-old male with active polymyositis.

not demonstrating a classical myositic picture with abnormal blood markers, muscles in PMR and GCA are likely to be abnormal.

There may be a fine line between the effects of inflammation from disease (PMR and GCA) and the catabolic effects of therapy (steroids) on muscle in patients. Amongst the many adverse effects of glucocorticoids, they trigger muscle atrophy, with a particular affinity for the atrophy of fast-twitch or type II muscle fibers $(90,91)$. This will often present as myopathy or muscle weakness, but due to the lack of a standardized definition of glucocorticoid-induced myopathy, reporting of myopathy due to therapy in PMR and GCA can prove inconsistent (92). Therefore, the management of steroid-induced myopathy can be challenging due to the difficulty in identifying myopathy before any clinical symptoms with the current means of investigation (93).

Can imaging help in characterizing the myopathy in this group of patients? Very little research in this area has been performed. Most studies have been focused on the diagnosis of PMR and GCA and responses to steroid therapy, based mainly on joint findings (94-97). Certainly, studies have demonstrated that quantitative ultrasound was able to show muscle changes associated to chronic use of steroids, but was unable to tell if the observed changes could be due to other causes including cachexia or sarcopenia $(98,99)$. A recent study showed that SWE detected a higher reduction in muscle stiffness over time in GCA patients on long term glucocorticoid who were also weaker (100). However, as patients with GCA (and PMR) tend to be older, and therefore more likely to be sarcopenic, these observed muscle changes have to be interpreted cautiously. If future research shows that SWE changes could potentially be evident before patients present with signs of weakness, then we may have an imaging tool that can direct appropriate management of steroidinduced myopathy, including preventative strategies to preserve muscle function. 
The fact that type II muscle fibers tend to be affected by steroid therapy suggests that techniques like MRI diffusion tensor imaging that are sensitive to changes in muscle microstructure could be potentially useful in understanding the pathogenesis of steroid-induced myopathy and its diagnosis $(80,101)$. Due to the inflammatory nature of PMR and GCA, T2 MRI could be able to identify the edema within the muscle itself, which could be contributing to pain and fatigue. The muscle atrophy due to the catabolic effects of glucocorticoids could be quantitatively measured to monitor muscle change over time. The challenge will be interpreting the findings and to tease out if the observed imaging changes are due to therapy (glucocorticoids), or to the inflammatory disease process. Previously, when patients with RA were treated with long term steroids, it was possible to tell when they had weaker strength compared to patients who did not receive steroid therapy $(102,103)$. This would have provided a useful cohort to compare imaging findings of the muscle, and changes could be attributed to the steroid therapy independent of the disease process. However, due to the complexities of modern therapy and the ethical limitations, such direct comparison studies may not be feasible. Another iatrogenic cause of myopathy is in IIM treated with glucocorticoids, which presents another challenging dilemma in differentiating between muscle changes due to therapy and that due to the inflammatory muscle disease per se. This proposes an unmet need for means to identify the exact cause of the myopathy to optimize management-an area for further exploration of imaging as a potential tool for this purpose.

Nevertheless, qMRI can differentiate the muscle properties between the ages and has been shown to correlate with muscle outcome measures. Therefore, it shows potential promise as a tool to help understand the varying factors that can affect muscle in rheumatic diseases (104).

\section{Rheumatoid Arthritis}

The predominant site of pathology in rheumatoid arthritis is in the joints. The articular joints are therefore the most commonly imaged structure in RA. However, there are many reasons for patients with RA to have weaker muscles, including impaired physical function and a greater tendency toward physical inactivity $(105,106)$. RA patients often present with lower muscle mass (107), which remains apparent in remission (105). A large proportion of RA patients report experiencing muscle problems or myopathy $(108,109)$. Histologically, RA is also associated with atrophy of type II muscle fibers, similar to the effects of glucocorticoids on muscle $(110,111)$. In addition, the pro-inflammatory state in inflammatory arthritis predisposes patients to a cachectic body composition-another reason for abnormal muscles in inflammatory arthritis $(112,113)$.

Despite the many causes of muscle involvement in inflammatory arthritis, there are relatively little muscle imaging data in RA. Reduced muscle strength is associated with disease activity in RA, and muscle function and physical activity are modifiable factors (2). Preliminary SWE of the muscles in RA shows some indication that muscles are less stiff compared to healthy individuals, but the results do not show statistical significance despite the fact that RA patients show reduced strength (114). The lack of differential findings from SWE studies suggests that muscle pathology in RA is less likely to be due to biomechanical properties of muscle. Quantitative MRI offers a different imaging perspective of muscle, and can provide further insight into the pathogenesis of muscle pathology in RA. Indeed, qMRI could be used to identify if rheumatic patients in remission still have muscle pathology, such as inflammation or fatty infiltration. This would identify whether effective treatment is improving muscle health, or if additional interventions, such as exercise, should be developed for a more holistic approach in patients with inflammatory arthritis.

Fatigue is a common symptom in many rheumatic conditions including inflammatory arthritis with significant impact on patients' lives (115). Although treatment including biological therapy can help improve symptoms of fatigue, they are not effective in all patients (116). Of note is that exercise has also been shown to reduce fatigue levels in RA (117); this suggests that modifying the muscles in inflammatory arthritis is a potential route to improving symptoms in patients. This is an area where the mechanism of action needs clarifying - an important cue for imaging, such as SWE and qMRI to help provide some insights.

\section{FUTURE PERSPECTIVES AND CONCLUSIONS}

The capabilities of novel imaging in muscle continue to be stretched to better understand the significance of the observations. Quantitative ultrasonographic techniques, such as muscle echo-intensity may reveal useful imaging biomarkers beyond the mechanical properties of SWE (88). The use of both SWE and qMRI in assessing muscles are relatively recent imaging advances. Due to the heterogeneous nature of muscle involvement in rheumatic diseases, a multi-parametric imaging approach may offer a clearer picture of the varying disease processes (118). Combining both techniques could result in a more powerful imaging combination that provides complementary understanding of muscle changes (119). The application of artificial intelligence (AI) in imaging in rheumatology has enhanced efficacy and efficiency in image interpretation (120). Unsurprisingly, AI in rheumatology imaging is currently confined to assessing the common joint abnormalities like joint synovitis, tenosynovitis, bone erosions and cartilage loss. Deep learning involving qMRI and SWE may accelerate the knowledge and application of these imaging techniques.

This perspective highlights that the involvement of muscle is widespread in many rheumatic diseases, which can also affect other conditions including the connective tissue diseases like systemic lupus erythematosus, Sjogren's syndrome and systemic sclerosis (1). Imaging, in particular the more recent novel techniques like SWE and qMRI, shows potential to improve the understanding of how muscle is affected in rheumatic diseases. Imaging has an important role in assessing potential interventions on preserving muscle function. Imaging has improved our knowledge of joint abnormalities, but it is now timely for a call to action for a more anatomically-holistic 
approach toward the understanding of the pathogenesis of rheumatic diseases, with due attention to the muscle.

\section{DATA AVAILABILITY STATEMENT}

This research is funded by the NIHR infrastructure at Leeds. The views expressed are those of the authors and not necessarily those of the NHS, the NIHR or the Department of Health.

\section{REFERENCES}

1. Altabas-Gonzalez I, Perez-Gomez N, Pego-Reigosa JM. How to investigate: suspected systemic rheumatic diseases in patients presenting with muscle complaints. Best Pract Res Clin Rheumatol. (2019) 33:101437. doi: 10.1016/j.berh.2019.101437

2. Uutela TI, Kautiainen HJ, Hakkinen AH. Decreasing muscle performance associated with increasing disease activity in patients with rheumatoid arthritis. PLoS ONE. (2018) 13:e0194917. doi: 10.1371/journal.pone.0194917

3. Kubínová K, Dejthevaporn R, Mann H, Machado PM, Vencovský J. The role of imaging in evaluating patients with idiopathic inflammatory myopathies. Clin Exp Rheumatol. (2018) 36:74-81. Available online at: https://www. clinexprheumatol.org/abstract.asp? $\mathrm{a}=13317$

4. Selva-O'Callaghan A, Gil-Vila A, Simó-Perdigó M, TralleroAraguás E, Alvarado-Cárdenas M, Pinal-Fernandez I. PET scan: nuclear medicine imaging in myositis. Curr Rheumatol Rep. (2019) 21:64. doi: 10.1007/s11926-019-0864-3

5. Mourtzakis M, Parry S, Connolly B, Puthucheary Z. Skeletal muscle ultrasound in critical care: a tool in need of translation. Ann Am Thorac Soc. (2017) 14:1495-503. doi: 10.1513/AnnalsATS.201612-967PS

6. Scott JM, Martin DS, Ploutz-Snyder R, Caine T, Matz T, Arzeno $\mathrm{NM}$, et al. Reliability and validity of panoramic ultrasound for muscle quantification. Ultrasound Med Biol. (2012) 38:165661. doi: 10.1016/j.ultrasmedbio.2012.04.018

7. Berger J, Bunout D, Barrera G, de la Maza MP, Henriquez S, Leiva $\mathrm{L}$, et al. Rectus femoris (RF) ultrasound for the assessment of muscle mass in older people. Arch Gerontol Geriatr. (2015) 61:33-8. doi: 10.1016/j.archger.2015.03.006

8. van Hooren B, Teratsias P, Hodson-Tole EF. Ultrasound imaging to assess skeletal muscle architecture during movements: a systematic review of methods, reliability, and challenges. J Appl Physiol. (2020) 128:97899. doi: 10.1152/japplphysiol.00835.2019

9. Drakonaki EE, Sudol-Szopinska I, Sinopidis C, Givissis P. High resolution ultrasound for imaging complications of muscle injury: is there an additional role for elastography? J Ultrasonogr. (2019) 19:137-44. doi: $10.15557 /$ JoU.2019.0020

10. Li Y, Snedeker JG. Elastography: modality-specific approaches, clinical applications, and research horizons. Skeletal Radiol. (2011) 40:38997. doi: 10.1007/s00256-010-0918-0

11. Sigrist RMS, Liau J, Kaffas AE, Chammas MC, Willmann JK. Ultrasound elastography: review of techniques and clinical applications. Theranostics. (2017) 7:1303-29. doi: 10.7150/thno. 18650

12. Barr RG, Nakashima K, Amy D, Cosgrove D, Farrokh A, Schafer F, et al. WFUMB guidelines and recommendations for clinical use of ultrasound elastography: part 2: breast. Ultrasound Med Biol. (2015) 41:1148-60. doi: 10.1016/j.ultrasmedbio.2015.03.008

13. Ferraioli G, Filice C, Castera L, Choi BI, Sporea I, Wilson SR, et al. WFUMB guidelines and recommendations for clinical use of ultrasound elastography: Part 3: liver. Ultrasound Med Biol. (2015) 41:116179. doi: 10.1016/j.ultrasmedbio.2015.03.007

14. Cosgrove D, Barr R, Bojunga J, Cantisani V, Chammas MC, Dighe $\mathrm{M}$, et al. WFUMB guidelines and recommendations on

\section{AUTHOR CONTRIBUTIONS}

MF and AT wrote the first draft of the manuscript. JB, RW, and AA edited and revised the manuscript. MF, JB, and AA contributed the figures. All authors revised the manuscript critically and approved the final version of the manuscript. All authors contributed to the article and approved the submitted version.

the clinical use of ultrasound elastography: part 4. Thyroid. Ultrasound Med Biol. (2017) 43:4-26. doi: 10.1016/j.ultrasmedbio.2016.06.022

15. Domenichini R, Pialat JB, Podda A, Aubry S. Ultrasound elastography in tendon pathology: state of the art. Skeletal Radiol. (2017) 46:164355. doi: 10.1007/s00256-017-2726-2

16. Dirrichs T, Quack V, Gatz M, Tingart M, Kuhl CK, Schrading S. Shear wave elastography (SWE) for the evaluation of patients with tendinopathies. Acad Radiol. (2016) 23:1204-13. doi: 10.1016/j.acra.2016.05.012

17. Sarabon N, Kozinc Z, Podrekar N. Using shear-wave elastography in skeletal muscle: a repeatability and reproducibility study on biceps femoris muscle. PLoS ONE. (2019) 14:e0222008. doi: 10.1371/journal.pone.0222008

18. Phan A, Lee J, Gao J. Ultrasound shear wave elastography in assessment of skeletal muscle stiffness in senior volunteers. Clin Imaging. (2019) 58:226. doi: 10.1016/j.clinimag.2019.06.006

19. Maslarska M, Weis C, Bode C, Hehrlein C. Shear wave elastography of peripheral muscle weakness in patients with chronic congestive heart failure. Ultrasound Med Biol. (2018) 44:2531-9. doi: 10.1016/j.ultrasmedbio.2018.08.011

20. Akagi R, Takahashi H. Effect of a 5-week static stretching program on hardness of the gastrocnemius muscle. Scand J Med Sci Sports. (2014) 24:950-7. doi: $10.1111 / \mathrm{sms} .12111$

21. Zhang ZJ, Ng GYF, Lee WC, Fu SN. Increase in passive muscle tension of the quadriceps muscle heads in jumping athletes with patellar tendinopathy. Scand J Med Sci Sports. (2017) 27:1099-104. doi: 10.1111/sms.12749

22. Itoigawa Y, Sperling JW, Steinmann SP, Chen Q, Song P, Chen S, et al. Feasibility assessment of shear wave elastography to rotator cuff muscle. Clin Anat. (2015) 28:213-8. doi: 10.1002/ca.22498

23. Flatres A, Aarab Y, Nougaret S, Garnier F, Larcher R, Amalric M, et al. Realtime shear wave ultrasound elastography: a new tool for the evaluation of diaphragm and limb muscle stiffness in critically ill patients. Crit Care. (2020) 24:34. doi: 10.1186/s13054-020-2745-6

24. Du LJ, He W, Cheng LG, Li S, Pan YS, Gao J. Ultrasound shear wave elastography in assessment of muscle stiffness in patients with Parkinson's disease: a primary observation. Clin Imaging. (2016) 40:107580. doi: 10.1016/j.clinimag.2016.05.008

25. Lacourpaille L, Hug F, Guevel A, Pereon Y, Magot A, Hogrel JY, et al. Noninvasive assessment of muscle stiffness in patients with Duchenne muscular dystrophy. Muscle Nerve. (2015) 51:284-6. doi: 10.1002/mus.24445

26. Gao J, He W, Du LJ, Chen J, Park D, Wells M, et al. Quantitative ultrasound imaging to assess the biceps brachii muscle in chronic post-stroke spasticity: preliminary observation. Ultrasound Med Biol. (2018) 44:193140. doi: 10.1016/j.ultrasmedbio.2017.12.012

27. Alfuraih AM, O'Connor P, Hensor E, Tan AL, Emery P, Wakefield RJ. The effect of unit, depth, and probe load on the reliability of muscle shear wave elastography: variables affecting reliability of SWE. J Clin Ultrasound. (2018) 46:108-15. doi: 10.1002/jcu.22534

28. Alfuraih AM, O'Connor P, Tan AL, Hensor E, Emery P, Wakefield RJ. An investigation into the variability between different shear wave elastography systems in muscle. Med Ultrasonogr. (2017) 19:392-400. doi: 10.11152/mu-1113

29. Kot BC, Zhang ZJ, Lee AW, Leung VY, Fu SN. Elastic modulus of muscle and tendon with shear wave ultrasound elastography: variations with different technical settings. PLOS ONE. (2012) 7:e44348. doi: 10.1371/journal.pone.0044348 
30. Faulkner JA, Larkin LM, Claflin DR, Brooks SV. Age-related changes in the structure and function of skeletal muscles. Clin Exp Pharmacol Physiol. (2007) 34:1091-6. doi: 10.1111/j.1440-1681.2007.04752.x

31. Kragstrup TW, Kjaer M, Mackey AL. Structural, biochemical, cellular, and functional changes in skeletal muscle extracellular matrix with aging. Scand J Med Sci Sports. (2011) 21:749-57. doi: 10.1111/j.1600-0838.2011.01377.x

32. Alfuraih AM, Tan AL, O'Connor P, Emery P, Wakefield RJ. The effect of ageing on shear wave elastography muscle stiffness in adults. Aging Clin Exp Res. (2019) 31:1755-63. doi: 10.1007/s40520-019-01139-0

33. Akagi R, Yamashita Y, Ueyasu Y. Age-related differences in muscle shear moduli in the lower extremity. Ultrasound Med Biol. (2015) 41:290612. doi: 10.1016/j.ultrasmedbio.2015.07.011

34. Yoshida K, Itoigawa Y, Maruyama Y, Saita Y, Takazawa Y, Ikeda H, et al. Application of shear wave elastography for the gastrocnemius medial head to tennis leg. Clin Anat. (2017) 30:114-9. doi: 10.1002/ca.22788

35. Sendur HN, Cindil E, Cerit MN, Kiliç P, Gültekin II, Oktar SÖ. Evaluation of effects of aging on skeletal muscle elasticity using shear wave elastography. Eur J Radiol. (2020) 128:109038. doi: 10.1016/j.ejrad.2020.109038

36. Eby SF, Cloud BA, Brandenburg JE, Giambini H, Song P, Chen S, et al. Shear wave elastography of passive skeletal muscle stiffness: influences of sex and age throughout adulthood. Clin Biomech. (2015) 30:227. doi: 10.1016/j.clinbiomech.2014.11.011

37. Wang CZ, Guo JY, Li TJ, Zhou Y, Shi W, Zheng YP. Age and sex effects on the active stiffness of vastus intermedius under isometric contraction. BioMed Res Int. (2017) 2017:9469548. doi: 10.1155/2017/9469548

38. Baumer TG, Dischler J, Davis L, Labyed Y, Siegal DS, van Holsbeeck M, et al. Effects of age and pathology on shear wave speed of the human rotator cuff. J Orthopaedic Res. (2018) 36:282-8. doi: 10.1002/jor.23641

39. Chodock E, Hahn J, Setlock CA, Lipps DB. Identifying predictors of upper extremity muscle elasticity with healthy aging. J Biomech. (2020) 103:109687. doi: 10.1016/j.jbiomech.2020.109687

40. Dresner MA, Rose GH, Rossman PJ, Muthupillai R, Manduca A, Ehman RL. Magnetic resonance elastography of skeletal muscle. J Magn Reson Imaging. (2001) 13:269-76. doi: 10.1002/1522-2586(200102)13:2<269::AID-JMRI1039>3.0.CO;2-1

41. Uffmann K, Maderwald S, Ajaj W, Galban CG, Mateiescu S, Quick HH, et al. In vivo elasticity measurements of extremity skeletal muscle with $\mathrm{MR}$ elastography. NMR Biomed. (2004) 17:181-90. doi: 10.1002/nbm.887

42. Bensamoun SF, Ringleb SI, Littrell L, Chen Q, Brennan M, Ehman RL, et al. Determination of thigh muscle stiffness using magnetic resonance elastography. J Magn Reson Imaging. (2006) 23:242-7. doi: 10.1002/jmri.20487

43. Zonnino A, Smith DR, Delgorio PL, Johnson CL, Sergi F. MM-MRE: a new technique to quantify individual muscle forces during isometric tasks of the wrist using MR elastography. IEEE Int Conf Rehabil Robot. (2019) 2019:270-5. doi: 10.1109/ICORR.2019.8779562

44. Creze M, Soubeyrand M, Yue JL, Gagey O, Maitre X, Bellin MF. Magnetic resonance elastography of the lumbar back muscles: a preliminary study. Clin Anat. (2018) 31:514-20. doi: 10.1002/ca.23065

45. Day J, Patel S, Limaye V. The role of magnetic resonance imaging techniques in evaluation and management of the idiopathic inflammatory myopathies. Semin Arthritis Rheum. (2017) 46:642-9. doi: 10.1016/j.semarthrit.2016.11.001

46. Nealon AR, Docking SI, Lucas PE, Connell DA, Koh ES, Cook JL. MRI findings are associated with time to return to play in first class cricket fast bowlers with side strain in Australia and England. J Sci Med Sport. (2019) 22:992-6. doi: 10.1016/j.jsams.2019.05.020

47. Crombe A, Marcellin PJ, Buy X, Stoeckle E, Brouste V, Italiano A, et al. Soft-tissue sarcomas: assessment of MRI features correlating with histologic grade and patient outcome. Radiology. (2019) 291:71021. doi: 10.1148/radiol.2019181659

48. Mercuri E, Jungbluth $H$, Muntoni F. Muscle imaging in clinical practice: diagnostic value of muscle magnetic resonance imaging in inherited neuromuscular disorders. Curr Opin Neurol. (2005) 18:52637. doi: 10.1097/01.wco.0000183947.01362.fe

49. Mercuri E, Pichiecchio A, Allsop J, Messina S, Pane M, Muntoni F. Muscle MRI in inherited neuromuscular disorders: past, present, and future. J Magn Reson Imaging. (2007) 25:433-40. doi: 10.1002/jmri.20804
50. Schmidt GP, Reiser MF, Baur-Melnyk A. Whole-body imaging of the musculoskeletal system: the value of MR imaging. Skeletal Radiol. (2007) 36:1109-19. doi: 10.1007/s00256-007-0323-5

51. Leung DG, Carrino JA, Wagner KR, Jacobs MA. Whole-body magnetic resonance imaging evaluation of facioscapulohumeral muscular dystrophy. Muscle Nerve. (2015) 52:512-20. doi: 10.1002/mus. 24569

52. Farrow M, Grainger AJ, Tan AL, Buch MH, Emery P, Ridgway JP, et al. Normal values and test-retest variability of stimulated-echo diffusion tensor imaging and fat fraction measurements in the muscle. Br J Radiol. (2019) 92:20190143. doi: 10.1259/bjr.20190143

53. Schlaffke L, Rehmann R, Rohm M, Otto LAM, de Luca A, Burakiewicz J, et al. Multi-center evaluation of stability and reproducibility of quantitative MRI measures in healthy calf muscles. NMR Biomed. (2019) 32:e4119. doi: 10.1002/nbm.4119

54. Ma J. Dixon techniques for water and fat imaging. J Magn Reson Imaging. (2008) 28:543-58. doi: 10.1002/jmri.21492

55. Yao L, Yip AL, Shrader JA, Mesdaghinia S, Volochayev R, Jansen $\mathrm{AV}$, et al. Magnetic resonance measurement of muscle T2, fatcorrected $\mathrm{T} 2$ and fat fraction in the assessment of idiopathic inflammatory myopathies. Rheumatology. (2015) 55:441-9. doi: 10.1093/rheumatology/kev344

56. Burakiewicz J, Hooijmans MT, Webb AG, Verschuuren J, Niks EH, Kan HE. Improved olefinic fat suppression in skeletal muscle DTI using a magnitude-based dixon method. Magn Reson Med. (2018) 79:1529. doi: $10.1002 / \mathrm{mrm} .26655$

57. Schlaeger S, Weidlich D, Klupp E, Montagnese F, Deschauer M, Schoser B, et al. Decreased water T2 in fatty infiltrated skeletal muscles of patients with neuromuscular diseases. NMR Biomed. (2019) 32:e4111. doi: 10.1002/nbm.4111

58. Scheel $M$, Prokscha $T$, von Roth $\mathrm{P}$, Winkler $\mathrm{T}$, Dietrich $\mathrm{R}$, Bierbaum S, et al. Diffusion tensor imaging of skeletal musclecorrelation of fractional anisotropy to muscle power. RoFo. (2013) 185:857-61. doi: 10.1055/s-0033-1335911

59. Sinha S, Sinha U, Edgerton VR. In vivo diffusion tensor imaging of the human calf muscle. J Magn Reson Imaging. (2006) 24:18290. doi: 10.1002/jmri.20593

60. Kermarrec E, Budzik JF, Khalil C, Le Thuc V, Hancart-Destee C, Cotten A. In vivo diffusion tensor imaging and tractography of human thigh muscles in healthy subjects. AJR Am J Roentgenol. (2010) 195:W3526. doi: 10.2214/AJR.09.3368

61. Fieremans E, Lemberskiy G, Veraart J, Sigmund EE, Gyftopoulos S, Novikov DS. In vivo measurement of membrane permeability and myofiber size in human muscle using time-dependent diffusion tensor imaging and the random permeable barrier model. NMR Biomed. (2017) 30:3612. doi: 10.1002/nbm.3612

62. Sigmund EE, Novikov DS, Sui D, Ukpebor O, Baete S, Babb JS, et al. Time-dependent diffusion in skeletal muscle with the random permeable barrier model (RPBM): application to normal controls and chronic exertional compartment syndrome patients. NMR Biomed. (2014) 27:51928. doi: $10.1002 / \mathrm{nbm} .3087$

63. Malis V, Sinha U, Csapo R, Narici M, Smitaman E, Sinha S. Diffusion tensor imaging and diffusion modeling: application to monitoring changes in the medial gastrocnemius in disuse atrophy induced by unilateral limb suspension. J Magn Reson Imaging. (2019) 49:165564. doi: 10.1002/jmri.26295

64. Barendregt AM, Bray TJP, Hall-Craggs MA, Maas M. Emerging quantitative MR imaging biomarkers in inflammatory arthritides. Eur J Radiol. (2019) 121:108707. doi: 10.1016/j.ejrad.2019.108707

65. Maggi L, Moscatelli M, Frangiamore R, Mazzi F, Verri M, de Luca A, et al. Quantitative muscle MRI protocol as possible biomarker in Becker muscular dystrophy. Clin Neuroradiol. (2020). doi: 10.1007/s00062-019-00875-0. [Epub ahead of print].

66. Nunez-Peralta C, Alonso-Perez J, Llauger J, Segovia S, Montesinos P, Belmonte I, et al. Follow-up of late-onset Pompe disease patients with muscle magnetic resonance imaging reveals increase in fat replacement in skeletal muscles. J Cachexia Sarcopenia Muscle. (2020). doi: 10.1002/jcsm.12555. [Epub ahead of print]. 
67. D'Souza A, Bolsterlee B, Herbert RD. Architecture of the medial gastrocnemius muscle in people who have had a stroke: a diffusion tensor imaging investigation. Clin Biomech. (2020) 74:27-33. doi: 10.1016/j.clinbiomech.2020.02.004

68. Heskamp L, van Nimwegen M, Ploegmakers MJ, Bassez G, Deux JF, Cumming SA, et al. Lower extremity muscle pathology in myotonic dystrophy type 1 assessed by quantitative MRI. Neurology. (2019) 92:e280314. doi: 10.1212/WNL.0000000000007648

69. Barnard AM, Willcocks RJ, Finanger EL, Daniels MJ, Triplett WT, Rooney $\mathrm{WD}$, et al. Skeletal muscle magnetic resonance biomarkers correlate with function and sentinel events in Duchenne muscular dystrophy. PLoS ONE. (2018) 13:e0194283. doi: 10.1371/journal.pone.0194283

70. Chinoy H, Lilleker JB. Pitfalls in the diagnosis of myositis. Best Pract Res Clin Rheumatol. (2020) 34:101486. doi: 10.1016/j.berh.2020.101486

71. van de Vlekkert J, Maas M, Hoogendijk JE, de Visser M, van Schaik IN. Combining MRI and muscle biopsy improves diagnostic accuracy in subacute-onset idiopathic inflammatory myopathy. Muscle Nerve. (2015) 51:253-8. doi: 10.1002/mus.24307

72. Pipitone N. Value of MRI in diagnostics and evaluation of myositis. Curr Opin Rheumatol. (2016) 28:625-30. doi: 10.1097/BOR.0000000000000326

73. Kubinova K, Mann H, Vencovsky J. MRI scoring methods used in evaluation of muscle involvement in patients with idiopathic inflammatory myopathies. Curr opin Rheumatol. (2017) 29:623-31. doi: 10.1097/BOR.0000000000000435

74. Connor A, Stebbings S, Anne Hung N, Hammond-Tooke G, Meikle G, Highton J. STIR MRI to direct muscle biopsy in suspected idiopathic inflammatory myopathy. J Clin Rheumatol. (2007) 13:341-5. doi: 10.1097/RHU.0b013e31815dca0a

75. Milisenda JC, Collado MV, Pinal-Fernandez I, Hormaza Jaramillo A, Faruch Bilfeld M, Cano MD, et al. Correlation between quantitative and semiquantitative magnetic resonance imaging and histopathology findings in dermatomyositis. Clin Exp Rheumatol. (2019) 37:633-40. Available online at: https://www.clinexprheumatol.org/abstract.asp? $\mathrm{a}=13003$

76. Huang ZG, Gao BX, Chen H, Yang MX, Chen XL, Yan R, et al. An efficacy analysis of whole-body magnetic resonance imaging in the diagnosis and follow-up of polymyositis and dermatomyositis. PLoS ONE. (2017) 12:e0181069. doi: 10.1371/journal.pone.0181069

77. Filli L, Maurer B, Manoliu A, Andreisek G, Guggenberger R. Whole-body MRI in adult inflammatory myopathies: do we need imaging of the trunk? Eur Radiol. (2015) 25:3499-507. doi: 10.1007/s00330-015-3783-3

78. Kadoba K, Mizukawa K, Nishimura K, Murabe H. Large vessel giant cell arteritis suggested by magnetic resonance imaging of the thigh: a potential mimicker of myositis, fasciitis and skeletal muscle vasculitis. Rheumatology (Oxford). (2019) 58:2211. doi: 10.1093/rheumatology/kez138

79. Ran J, Ji S, Morelli JN, Wu G, Li XM. The diagnostic value of T2 maps and rs-EPI DWI in dermatomyositis. Br J Radiol. (2019) 92:20180715. doi: 10.1259/bjr.20180715

80. Qi J, Olsen NJ, Price RR, Winston JA, Park JH. Diffusion-weighted imaging of inflammatory myopathies: polymyositis and dermatomyositis. J Magn Reson Imaging. (2008) 27:212-7. doi: 10.1002/jmri.21209

81. Kim HK, Laor T, Horn PS, Racadio JM, Wong B, Dardzinski BJ. T2 mapping in Duchenne muscular dystrophy: distribution of disease activity and correlation with clinical assessments. Radiology. (2010) 255:899908. doi: 10.1148/radiol.10091547

82. Gaeta M, Scribano E, Mileto A, Mazziotti S, Rodolico C, Toscano A, et al. Muscle fat fraction in neuromuscular disorders: dual-echo dual-flipangle spoiled gradient-recalled MR imaging technique for quantification-a feasibility study. Radiology. (2011) 259:487-94. doi: 10.1148/radiol.10101108

83. Sigmund EE, Baete SH, Luo T, Patel K, Wang D, Rossi I, et al. MRI assessment of the thigh musculature in dermatomyositis and healthy subjects using diffusion tensor imaging, intravoxel incoherent motion and dynamic DTI. Eur Radiol. (2018) 28:5304-15. doi: 10.1007/s00330-018-5458-3

84. Botar-Jid C, Damian L, Dudea SM, Vasilescu D, Rednic S, Badea R. The contribution of ultrasonography and sonoelastography in assessment of myositis. Med Ultrasonogr. (2010) 12:120-6. Available online at: https:// www.medultrason.ro/medultrason/index.php/medultrason/article/view/212

85. Berko NS, Hay A, Sterba Y, Wahezi D, Levin TL. Efficacy of ultrasound elastography in detecting active myositis in children: can it replace MRI? Pediatr Radiol. (2015) 45:1522-8. doi: 10.1007/s00247-015-3350-8
86. Alfuraih AM, O’Connor P, Tan AL, Hensor EMA, Ladas A, Emery P, et al. Muscle shear wave elastography in idiopathic inflammatory myopathies: a case-control study with MRI correlation. Skeletal Radiol. (2019) 48:120919. doi: 10.1007/s00256-019-03175-3

87. McCullough MB, Domire ZJ, Reed AM, Amin S, Ytterberg SR, Chen Q, et al. Evaluation of muscles affected by myositis using magnetic resonance elastography. Muscle Nerve. (2011) 43:585-90. doi: 10.1002/mus.21923

88. Bachasson D, Dubois GJR, Allenbach Y, Benveniste O, Hogrel JY. Muscle shear wave elastography in inclusion body myositis: feasibility, reliability and relationships with muscle impairments. Ultrasound Med Biol. (2018) 44:1423-32. doi: 10.1016/j.ultrasmedbio.2018.03.026

89. Ponte C, Martins-Martinho J, Luqmani RA. Diagnosis of giant cell arteritis. Rheumatology (Oxford). (2020) 59:iii516. doi: 10.1093/rheumatology/kez553

90. Schakman O, Kalista S, Barbe C, Loumaye A, Thissen JP. Glucocorticoidinduced skeletal muscle atrophy. Int J Biochem Cell Biol. (2013) 45:216372. doi: 10.1016/j.biocel.2013.05.036

91. Lofberg E, Gutierrez A, Wernerman J, Anderstam B, Mitch WE, Price SR, et al. Effects of high doses of glucocorticoids on free amino acids, ribosomes and protein turnover in human muscle. Eur J Clin Invest. (2002) 32:345-53. doi: 10.1046/j.1365-2362.2002.00993.x

92. Harris E, Tiganescu A, Tubeuf S, Mackie SL. The prediction and monitoring of toxicity associated with long-term systemic glucocorticoid therapy. Curr Rheumatol Rep. (2015) 17:513. doi: 10.1007/s11926-0150513-4

93. Minetto MA, Rainoldi A, Jabre JF. The clinical use of macro and surface electromyography in diagnosis and follow-up of endocrine and drug-induced myopathies. J Endocrinol Invest. (2007) 30:7916. doi: 10.1007/BF03350820

94. Mackie SL, Pease CT, Fukuba E, Harris E, Emery P, Hodgson R, et al. Wholebody MRI of patients with polymyalgia rheumatica identifies a distinct subset with complete patient-reported response to glucocorticoids. Ann Rheum Dis. (2015) 74:2188-92. doi: 10.1136/annrheumdis-2015-207395

95. McGonagle D, Pease C, Marzo-Ortega H, O'Connor P, Gibbon W, Emery $\mathrm{P}$. Comparison of extracapsular changes by magnetic resonance imaging in patients with rheumatoid arthritis and polymyalgia rheumatica. J Rheumatol. (2001) 28:1837-41. Available online at: https://www.jrheum.org/content/28/ 8/1837.long

96. Mori S, Koga Y, Ito K. Clinical characteristics of polymyalgia rheumatica in Japanese patients: evidence of synovitis and extracapsular inflammatory changes by fat suppression magnetic resonance imaging. Mod Rheumatol. (2007) 17:369-75. doi: 10.3109/s10165-007-0595-6

97. Matteson EL, Maradit-Kremers H, Cimmino MA, Schmidt WA, Schirmer $\mathrm{M}$, Salvarani C, et al. Patient-reported outcomes in polymyalgia rheumatica. J Rheumatol. (2012) 39:795-803. doi: 10.3899/jrheum.110977

98. Martucci MG, McIlduff CE, Shin C, Gutierrez HV, Nam JY, Greenstein P, et al. Quantitative ultrasound of muscle can detect corticosteroid effects. Clin Neurophysiol. (2019) 130:1460-4. doi: 10.1016/j.clinph.2019.04.709

99. Webster JM, Fenton CG, Langen R, Hardy RS. Exploring the interface between inflammatory and therapeutic glucocorticoid induced bone and muscle loss. Int J Mol Sci. (2019) 20:5768. doi: 10.3390/ijms20225768

100. Alfuraih AM, Tan AL, O'Connor P, Emery P, Mackie S, Wakefield RJ. Reduction in stiffness of proximal leg muscles during the first 6 months of glucocorticoid therapy for giant cell arteritis: a pilot study using shear wave elastography. Int J Rheum Dis. (2019) 22:18919. doi: 10.1111/1756-185X.13667

101. Damon BM, Froeling M, Buck AK, Oudeman J, Ding Z, Nederveen AJ, et al. Skeletal muscle diffusion tensor-MRI fiber tracking: rationale, data acquisition and analysis methods, applications and future directions. NMR Biomed. (2017) 30:e3563. doi: 10.1002/nbm.3563

102. Danneskiold-Samsoe B, Grimby G. Isokinetic and isometric muscle strength in patients with rheumatoid arthritis. The relationship to clinical parameters and the influence of corticosteroid. Clin Rheumatol. (1986) 5:459-67.

103. Rothstein JM, Delitto A, Sinacore DR, Rose SJ. Muscle function in rheumatic disease patients treated with corticosteroids. Muscle Nerve. (1983) 6:12835. doi: $10.1002 /$ mus. 880060208

104. Farrow M, Biglands J, Tanner SF, Clegg A, Brown L, Hensor EMA, et al. The effect of ageing on skeletal muscle as assessed by quantitative MR imaging: an association with frailty and muscle 
strength. Aging Clin Exp Res. (2020). doi: 10.1007/s40520-020-0 1530-2. [Epub ahead of print].

105. Lemmey AB, Wilkinson TJ, Clayton RJ, Sheikh F, Whale J, Jones HS, et al. Tight control of disease activity fails to improve body composition or physical function in rheumatoid arthritis patients. Rheumatology (Oxford). (2016) 55:1736-45. doi: 10.1093/rheumatology/kew243

106. Hanaoka BY, Ithurburn MP, Rigsbee CA, Bridges SL Jr., Moellering DR, et al. Chronic inflammation in rheumatoid arthritis and mediators of skeletal muscle pathology and physical impairment: a review. Arthritis Care Res. (2019) 71:173-7. doi: 10.1002/acr.23775

107. Baker JF, Von Feldt J, Mostoufi-Moab S, Noaiseh G, Taratuta E, Kim W, et al. Deficits in muscle mass, muscle density, and modified associations with fat in rheumatoid arthritis. Arthritis Care Res. (2014) 66:16128. doi: 10.1002/acr.22328

108. Ekdahl C, Andersson SI, Svensson B. Muscle function of the lower extremities in rheumatoid arthritis and osteoarthrosis. A descriptive study of patients in a primary health care district. J Clin Epidemiol. (1989) 42:94754. doi: 10.1016/0895-4356(89)90159-5

109. Miro O, Pedrol E, Casademont J, Garcia-Carrasco M, Sanmarti R, Cebrian $\mathrm{M}$, et al. Muscle involvement in rheumatoid arthritis: clinicopathological study of 21 symptomatic cases. Semin Arthritis Rheum. (1996) 25:4218. doi: 10.1016/S0049-0172(96)80007-2

110. Brooke MH, Kaplan H. Muscle pathology in rheumatoid arthritis, polymyalgia rheumatica, and polymyositis: a histochemical study. Arch Pathol. (1972) 94:101-18.

111. Edstrom L, Nordemar R. Differential changes in type I and type II muscle fibres in rheumatoid arthritis. A biopsy study. Scand J Rheumatol. (1974) 3:155-60. doi: 10.3109/03009747409097142

112. Roubenoff R, Roubenoff RA, Cannon JG, Kehayias JJ, Zhuang H, DawsonHughes B, et al. Rheumatoid cachexia: cytokine-driven hypermetabolism accompanying reduced body cell mass in chronic inflammation. J Clin Invest. (1994) 93:2379-86. doi: 10.1172/JCI117244

113. Engvall IL, Elkan AC, Tengstrand B, Cederholm T, Brismar K, Hafstrom I. Cachexia in rheumatoid arthritis is associated with inflammatory activity, physical disability, and low bioavailable insulin-like growth factor. Scand J Rheumatol. (2008) 37:321-8. doi: 10.1080/03009740802055984
114. Alfuraih AM, Tan AL, O’Connor P, Emery P, Wakefield RJ. Muscle stiffness in rheumatoid arthritis is not altered or associated with muscle weakness: a shear wave elastography study. Mod Rheumatol. (2020) 30:61725. doi: 10.1080/14397595.2019.1645374

115. Seifert O, Baerwald C. Impact of fatigue on rheumatic diseases. Best Pract Res Clin Rheumatol. (2019) 33:101435. doi: 10.1016/j.berh.2019.101435

116. Almeida C, Choy EH, Hewlett S, Kirwan JR, Cramp F, Chalder T, et al. Biologic interventions for fatigue in rheumatoid arthritis. Cochrane Database Syst Rev. (2016) 2016:CD008334. doi: 10.1002/14651858.CD008334.pub2

117. Azeez M, Clancy C, O’Dwyer T, Lahiff C, Wilson F, Cunnane G. Benefits of exercise in patients with rheumatoid arthritis: a randomized controlled trial of a patient-specific exercise programme. Clin Rheumatol. (2020) 39:178392. doi: 10.1007/s10067-020-04937-4

118. Bryant ND, Li K, Does MD, Barnes S, Gochberg DF, Yankeelov TE, et al. Multi-parametric MRI characterization of inflammation in murine skeletal muscle. NMR Biomed. (2014) 27:716-25. doi: 10.1002/nbm.3113

119. Giambini H, Hatta T, Rezaei A, An KN. Extensibility of the supraspinatus muscle can be predicted by combining shear wave elastography and magnetic resonance imaging-measured quantitative metrics of stiffness and volumetric fat infiltration: a cadaveric study. Clin Biomech. (2018) 57:1449. doi: 10.1016/j.clinbiomech.2018.07.001

120. Stoel B. Use of artificial intelligence in imaging in rheumatologycurrent status and future perspectives. RMD Open. (2020) 6:e001063. doi: 10.1136/rmdopen-2019-001063

Conflict of Interest: The authors declare that the research was conducted in the absence of any commercial or financial relationships that could be construed as a potential conflict of interest.

Copyright () 2020 Farrow, Biglands, Alfuraih, Wakefield and Tan. This is an openaccess article distributed under the terms of the Creative Commons Attribution License (CC BY). The use, distribution or reproduction in other forums is permitted, provided the original author(s) and the copyright owner(s) are credited and that the original publication in this journal is cited, in accordance with accepted academic practice. No use, distribution or reproduction is permitted which does not comply with these terms. 